\title{
Preliminary examination of Coaching in Context with clients with spinal cord injury
}

\author{
Caitlin Cadematori $^{1} \cdot$ Bernadette Alpajora $^{1} \cdot$ Taylor Sivori $^{1} \cdot$ Samantha Betz ${ }^{1} \cdot$ Nicole Gerhardt $^{1} \cdot$ Winnie Dunn $^{2}$. \\ M. J. Mulcahey $\mathbb{B}^{1}$
}

Received: 5 July 2020 / Revised: 18 January 2021 / Accepted: 18 February 2021

(c) The Author(s), under exclusive licence to International Spinal Cord Society 2021

\begin{abstract}
Study design Repeated measures pilot study.

Objectives This study examined Coaching in Context when introduced to community-dwelling adults with spinal cord injury (SCI).

Setting Urban community.

Methods Three volunteers participated in up to ten, 45-60-min Coaching in Context sessions. Number of coaching sessions was recorded. Usefulness of Coaching in Context was examined by the Canadian Occupational Performance Measure (COPM), Goal Attainment Scaling (GAS), and the Moorong Self-efficacy Scale (MSES). Data were examined descriptively. Results Preliminary examination of Coaching in Context revealed successful implementation with adults with SCI living in the community. Mean COPM performance and satisfaction scores increased by $2.55(\mathrm{SD}=2.25)$ and $4.27(\mathrm{SD}=2.41)$, respectively. With the exception of one, each goal achieved or exceeded GAS expected level. Changed MSES scores ranged from +7 to +16 .
\end{abstract}

Conclusions The ability to implement and evaluate Coaching in Context with three adults with SCI was demonstrated. Improvement in goals established for coaching was also documented.

\section{Introduction}

Over the last decade, there have been a growing number of studies on coaching in the healthcare literature. The primary focus of health coaching is to reduce healthcare costs through behavior change [1, 2]. Health coaching targets changes in behavior for health promotion, to better selfmanage chronic conditions [3-7], and to prevent medical complications due to disease or disability [8,9], including spinal cord injury (SCI) [10-13]. Studies on health coaching with adults living with chronic conditions have demonstrated improvement in self-efficacy, perceived health status, and health-related quality of life, and decline in health

M. J. Mulcahey

Maryjane.mulcahey@jefferson.edu

1 Center for Outcomes and Measurement, Jefferson College of Rehabilitation Sciences, Thomas Jefferson University, Philadelphia, PA, USA

2 University of Missouri, Columbia, MO, USA distress and depression [3, 6, 10, 14-17]. While outcomes of health coaching can be central to health-related quality of life, health coaching does not directly target outcomes on meaningful participation in the context of everyday living.

Participation in everyday living is the goal of rehabilitation. Following SCI, participation in self-chosen activities is positively associated with social-emotional and physical health, and quality of life [18], while gainful employment is associated greater physical health and improved financial independence, sense of well-being, self-efficacy, and selfesteem [19-23]. Although substantial evidence cites the benefits of participation on the health and wellness of persons with SCI, there is far less literature describing interventions and approaches that focus directly on maintaining or improving participation [18, 24, 25].

In contrast to health coaching, occupation-based [26-28] and occupational performance coaching (OPC) [29-31] are coaching interventions used by occupational therapists that directly target participation. Occupation-based coaching and OPC have been described primarily for mothers of children with autism spectrum disorders (ASD) [26-29], but have also been used with persons with newly acquired stroke [32]. 
Table 1 Participant demographics.

\begin{tabular}{|c|c|c|c|c|c|c|c|c|c|c|}
\hline \multirow[t]{2}{*}{ ID } & \multirow[t]{2}{*}{ Age } & \multirow[t]{2}{*}{ LOI } & \multirow[t]{2}{*}{ AIS } & \multirow[t]{2}{*}{ Cause of SCI } & \multirow{2}{*}{$\begin{array}{l}\text { Years } \\
\text { since SCI }\end{array}$} & \multirow{2}{*}{$\begin{array}{l}\text { Education } \\
\text { completed }\end{array}$} & \multicolumn{2}{|l|}{ Occupation } & \multicolumn{2}{|l|}{ Living arrangement } \\
\hline & & & & & & & At injury & At enrollment & At injury & At enrollment \\
\hline 100 & 41 & C5 & A & Diving & 28 & 2-yr college & Student & Unemployed & Grandparents' home & Apartment \\
\hline 101 & 25 & $\mathrm{C} 4$ & $\mathrm{C}$ & Vascular & 3 & 4-yr college & Employed & Unemployed & Apartment & Parents' home \\
\hline 102 & 31 & C6 & $\mathrm{C}$ & Fall & 1 & 4-yr college & $\begin{array}{l}\text { Pharmacy } \\
\text { student }\end{array}$ & $\begin{array}{l}\text { Pharmacy } \\
\text { student }\end{array}$ & College housing & Parents' home \\
\hline
\end{tabular}

$I D$ study unique number identification, $L O I$ level of injury according to the International Classification of Spinal Cord Injury, $C$ (\#) cervical level of injury, AIS American Spinal Injury Association Impairment Scale, $A$ motor and sensory complete injury, $C$ motor incomplete injury, $\operatorname{Yr}(s)$ year (years).

Literature indicates that coaching parents of children with ASD within the context of activities, environments, and routines promotes problem solving, which leads to the achievement of immediate goals related to everyday living, and an increased sense of competence in the parenting role [33].

Coaching in Context is a coaching process [34] that uses skillful, constructive conversation that involves client-centeredness, coach presence, active listening, and powerful and reflective questioning to create awareness, action plans and solutions to challenges that interfere with participating in necessary, expected and desired activities. It draws heavily on the tenets of positive psychology [35], is solution focused, and employs evidence-informed techniques including motivational interviewing [36]. Coaching in Context is an interprofessional coaching approach as opposed to an occupational therapy intervention, situates clients as resourceful, fully complete, and experts in their lives, and promotes problem-solving skills that are solution focused. Coaching in Context is contextualized by the personal, physical, social, cultural, virtual, spiritual, and socioeconomic lived environments, and by the requirements and innate desires for competent and satisfying everyday living. The purpose of this study was to examine Coaching in Context with adults with SCI living in the community.

\section{Methods}

\section{Study design}

A repeated measures pilot study was implemented with three consented individuals who participated in Coaching in Context. The Institutional Review Board of Thomas Jefferson University, Philadelphia, PA, USA approved this study (IRB\#18D.487).

\section{Participants}

The three participants were adults with tetraplegia resulting from chronic (>3 months duration) SCI who were living in the community (Table 1). All participants were Caucasian, non-Hispanic, and never married. Recruitment was by way of convenience, as the participants were known to the investigators and had previously expressed interest in research participation.

\section{Data collection}

The National Institute of Neurological Disorders and Stroke SCI Common Data Elements for Demographics were used to record characteristics of each participant [37].

The Canadian Occupational Performance Measure (COPM) and Goal Attainment Scaling (GAS) were administered at baseline and following completion of Coaching in Context. The COPM [38] is a self-reported measure administered using a semi-structured interview that involves five general steps (http://www.thecopm.ca/learn/\#wp-videolightbox/4/). The first step of the COPM interview is to identify desired, required, or expected activities that are challenging or problematic. The second step identifies the importance of each problem area in order to prioritize them as goals for intervention (third step). The goals identified for intervention are then rated by the client on a scale ranging from 1 to 10 ( 1 = "cannot perform," "very unsatisfied"; 10 $=$ "performs well," "very satisfied"). The fifth step involves reassessing performance and satisfaction of the problem areas. Although it is used outside of occupational therapy, the COPM semi-structured interview was developed by occupational therapists who practice client-centered occupation-based therapy, and thus problems are categorized into one of three occupations: productivity, self-care, and leisure. Strong psychometric properties are established [39, 40], including with the SCI population [41]. The COPM aligns well with Coaching in Context, owing to its client-centeredness and purpose, namely, targeting meaningful everyday activities and participation as goals for coaching. In this study, the COPM was used to establish and evaluate coaching goals.

In addition to scoring the goals using the COPM performance and satisfaction scales, we also applied GAS [42] 
to the COPM goals. GAS scores range from -2 to +2 , with 0 reflecting the expected outcome, negative values reflecting outcomes which do not meet expected goal attainment, and positive values representing outcomes which exceed expected goal attainment. We used methods to increase the objectivity of GAS [43, 44]. Specifically, the GAS scaling was developed collaboratively between the coach and client, and the description for each numerical score $(-2$ to +2$)$ was then revised for clarity and objectivity by an occupational therapy researcher (last author) with experience in GAS, in collaboration with the coaches (first four authors). These methods reduce the incidence of identifying simplistic, unrealistic, and unclear descriptions for the numerical scores [42]. After coaching, participants assigned GAS scores for each of their COPM goals.

The Moorong Self-efficacy Scale (MSES) [45] was also administered, as one of the intended outcomes of Coaching in Context is self-efficacy for problem-solving and solution finding. It consists of 16 items designed to measure selfefficacy in participation in daily activities and social participation in persons with SCI. Social participation items assess efficacy in maintaining contact, friendships, family relationships, managing unexpected problems, having a fulfilling lifestyle, leisure, task accomplishment, and household participation [45]. Daily activity items assess efficacy in health, work, task accomplishment, personal hygiene, persistence in learning, having a fulfilling lifestyle, and household participation [45]. Responses were recorded on a seven-point Likert scale ranging from 1 (very uncertain) to 7 (very certain) for each item [45]. Higher scores reflect greater self-efficacy. Preliminary psychometric research reported test-retest reliability of $0.74(p<0.001)$ with adequate internal validity $(r=0.55)$ [46]. The MSES was administered at baseline and again following Coaching in Context.

\section{Coaching in Context}

Coaching in Context uses an overarching cyclical framework (Fig. 1) informed by the coaching model described by the School of Coach Mastery (https://www.schoolofcoa chingmastery.com/) (Table 2). The connection phase of coaching establishes trusting and authentic relationships that provide a basis for partnership. Powerful and reflective questioning fosters clarity about bridges and barriers (for goal achievement) (Fig. 2). With clarity, the client is better poised to recognize opportunities, to be receptive to possibilities, and to become resourceful to define action plans and solutions. These opportunities, possibilities, and resourcefulness create bridges to goals. Coaches utilize skillful dialogue and conversations throughout each phase to create an authentic coaching session focused on solutions. Within a given session, movement back and forth

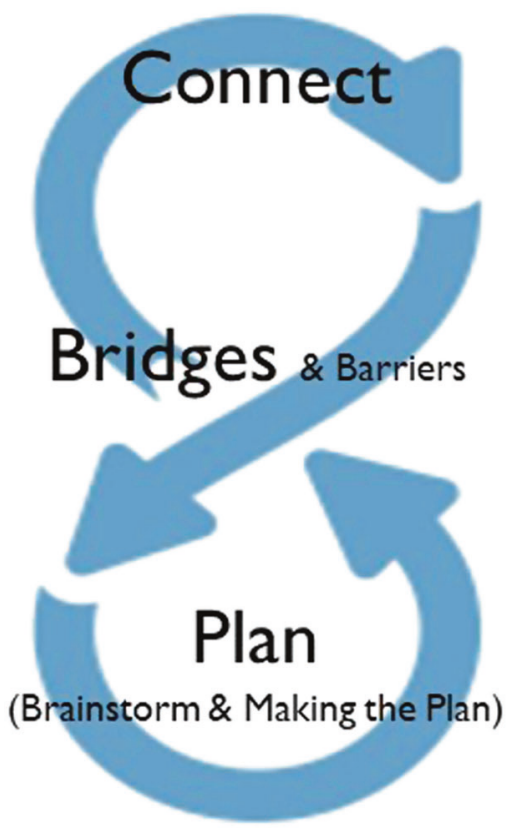

Fig. 1 Model of Coaching in Context. Informed by the teachings of the School of Coach Mastery. Connection focuses on establishing a positive and trusting coaching relationship, without which a client may be resistant to gaining clarity on goals and aspirations. With a trusting coaching relationship, client is receptive to different perspectives and possibilities, able to crate bridges to overcome barriers. With clarity, client is able to create definitive action plans toward goals and desires.

among the phases is seamless and guided by clients' responses to questions including content and tone of verbal responses, silences during thought and reflection and other indicators of the client's desire and readiness for clarity and action. Each session closes with definitive action(s) and plan(s) defined by the client that will be carried out prior to the next coaching session.

Each Coaching in Context session was conducted faceto-face at a mutually agreed upon, quiet location and lasted between 45 and $60 \mathrm{~min}$. Participants engaged in between four and eight coaching sessions over an 11-week period. Coaching sessions were audio or video recorded.

\section{Coaches and coaching training}

Four graduate students (first four authors) underwent formal coach training by the sixth author (WD), who is a certified Positive Psychology Master Coach. Training consisted of 10 ( 2 coaches) and 15 ( 2 coaches) synchronous, online, 60 min, weekly sessions, which focused on core coaching principles, the conceptual framework for coaching (Fig. 1 and Table 2) and the structure of a coaching session. Training included discussion, live coaching demonstrations, and review of coaching exemplars. Between training sessions, coaching skills were practiced and videos of practice sessions were uploaded to TORSH Talent ${ }^{\circledR}$ (https://torshta 
lent.com/), a secure, HIPAA compliant, web-based platform designed to support online coach training. The practice video sessions were reviewed by the last two authors, who used them to provide direct feedback on opportunities to improve coaching skills.

\section{Data analysis}

Audio and video recordings for each coaching session were transcribed verbatim. The study data were deidentified, uploaded to a secure research drive, and hard copies were stored in a secure cabinet at the research facility. We examined the distribution of combined COPM performance and satisfaction scores before and after coaching. We also examined change scores for each participant, and considered a two-point change in COPM scores as a meaningful improvement [38]. GAS change scores were examined descriptively to determine if the expected outcome (score of "0") was achieved [47]. Change MSES scores were also examined.

\section{Results}

Each of the three coaching participants completed Coaching in Context baseline and follow-up assessments. Two participants (100 and 101) had eight coaching sessions over 10 weeks, and one participant (102) completed four coaching sessions over 5 weeks. A total of 11 COPM goals were identified across the participants. Each COPM goal was associated with one of three domains: leisure $(n=2)$, self-care $(n=4)$, and productivity $(n=5)$.

COPM score distributions are shown in Fig. 3. Performance scores ranged between 1 and 7 at baseline, and 4 and 8 at follow-up. Satisfaction scores ranged from 1 to 3 at baseline, and 3 to 10 at follow-up. After Coaching in Context, mean performance and satisfaction scores increased by $2.55(\mathrm{SD}=2.25)$ and $4.27(\mathrm{SD}=2.41)$, respectively. COPM scores for each of the participants' goals are shown in Fig. 4. After coaching, there was meaningful improvement in performance in six $(56 \%)$ goals, three $(27 \%)$ goals improved by one point, and the remaining two showed no change. After coaching, improvement in satisfaction was meaningful for all 11 goals.

Table 3 shows the GAS scores assigned to each COPM goal following the completion of Coaching in Context. Each participant achieved or exceeded the expected level of outcome for each goal, with the exception of one goal (ID 102) that was assigned a score of -1 (slightly less than expected). MSES scores improved for all three participants, with change scores ranging from +7 to +16 (Table 3). 


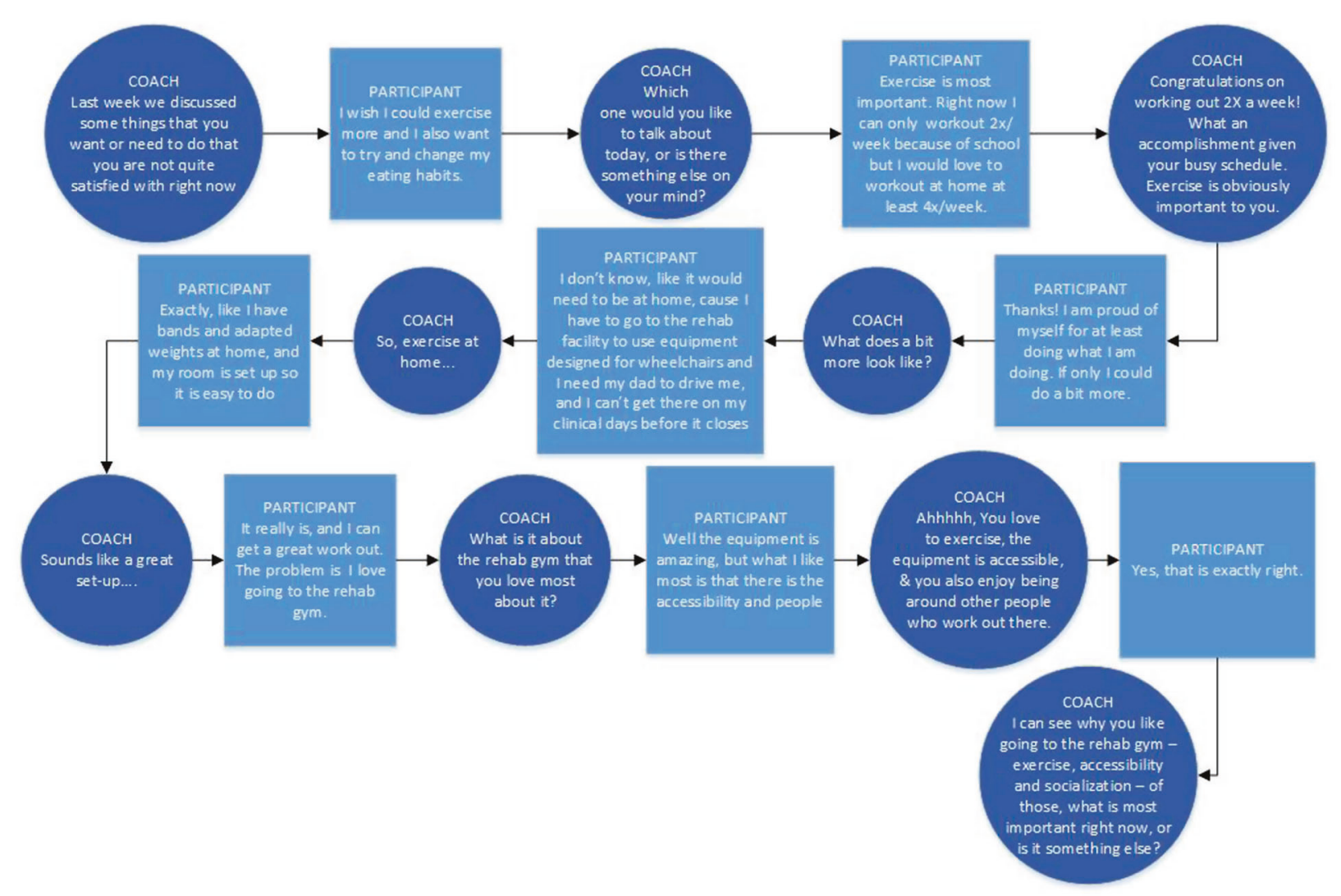

Fig. 2 Example coaching questions in clarify phase of coaching. coach to help client gain clarity about challenges interfering with more Short portion of a larger coaching session focused on desire for more frequent exercise and about priorities. frequent exercise. Open-ended and reflective questions are used by the

Fig. 3 Distribution of COPM scores at baseline and after coaching. Data reflect 11 COPM goals across three coaching participants.

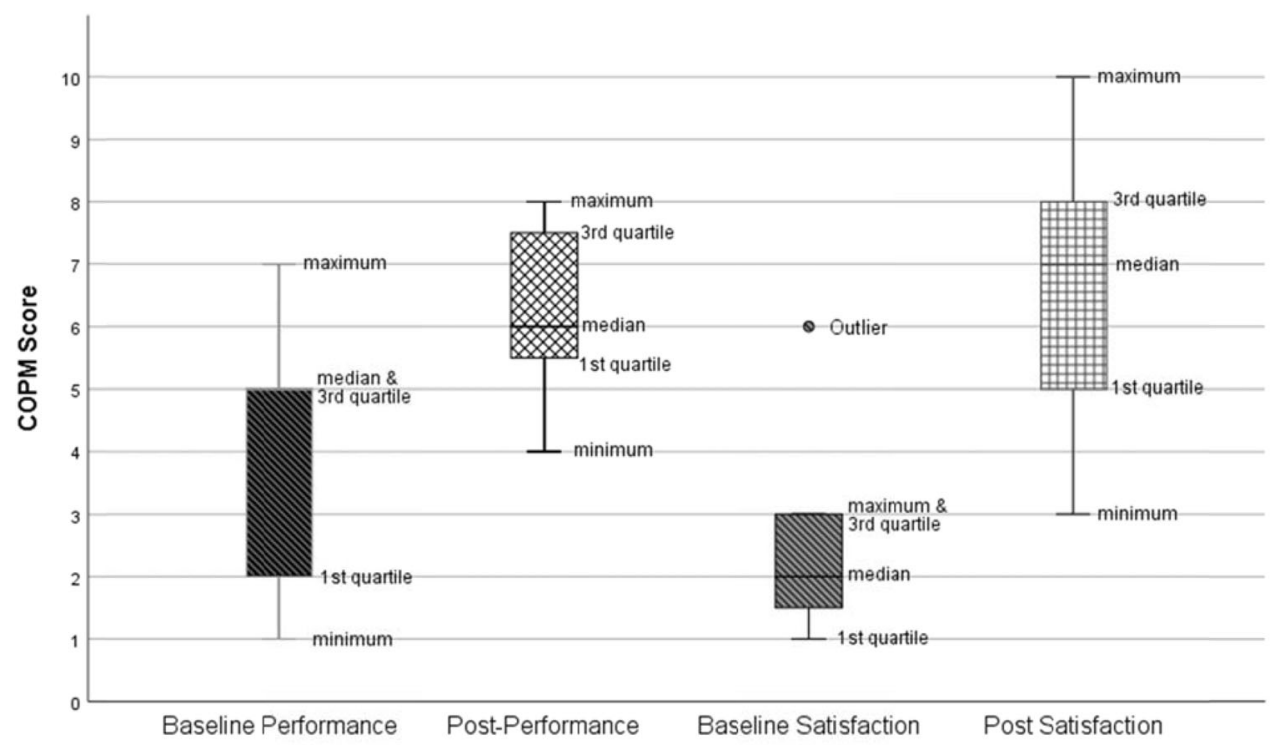

\section{Discussion}

This study demonstrates implementation of Coaching in Context with three adults with SCI. Each participant was able to identify goals for coaching, and rate their performance of and satisfaction with each goal using the COPM response categories. Moreover, they were able to work with their coaches to develop meaningful GAS for each of their goals. Coaching outcomes with these three participants, as measured by the COPM and GAS, were 
Fig. 4 COPM performance and satisfaction change scores. Participant 100 (a), 101 (b), and 102 (c).
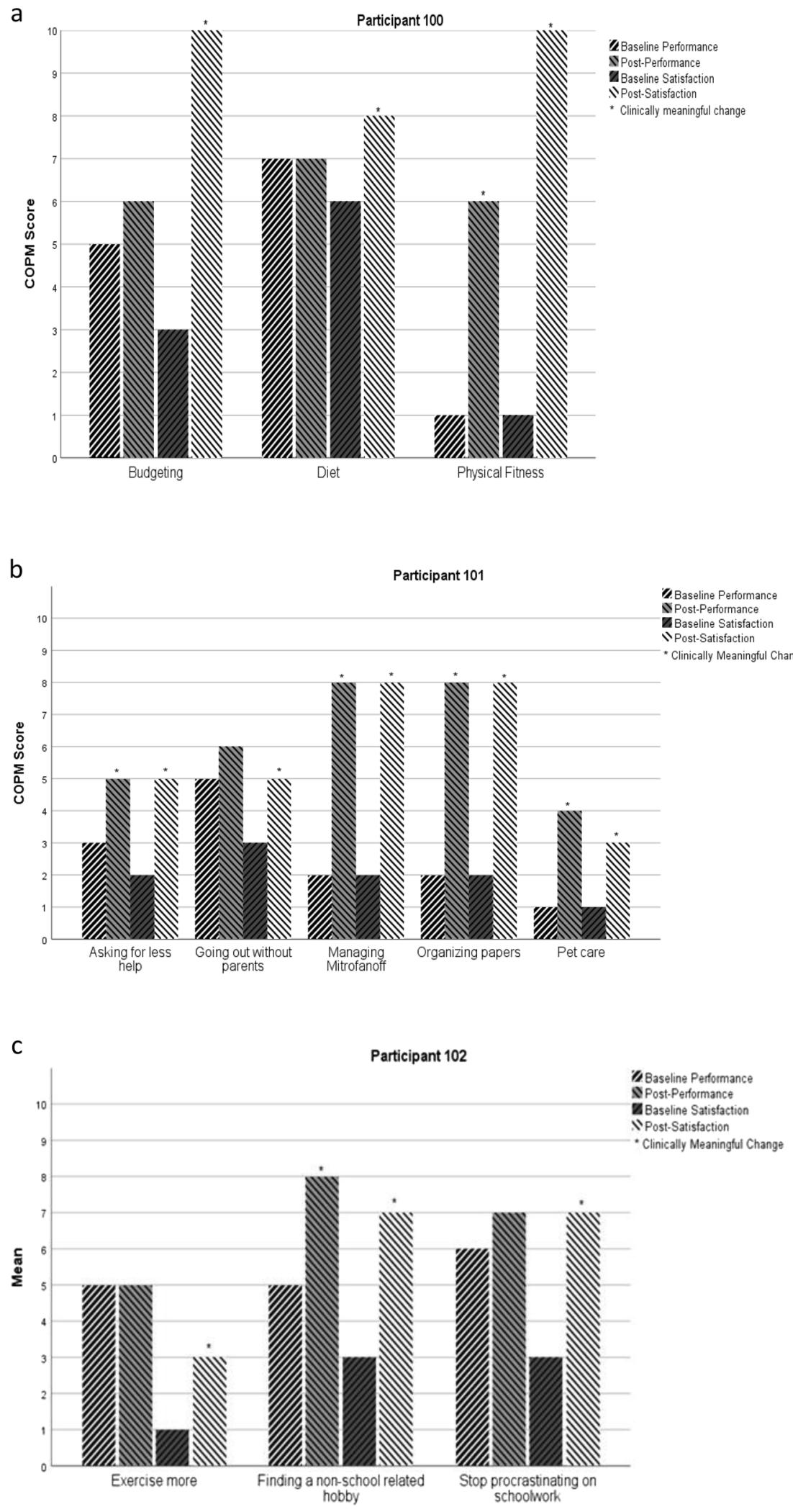

positive with improvements seen in performance of the majority of goals and in satisfaction with all of the goals. It is interesting to note that improvement in performance of most of the self-care goals met or exceeded the two-point threshold for meaningful change. Participants 100 and 102 reported improved performance in physical fitness by five- 
Table 3 GAS and MSES outcomes.

\begin{tabular}{|c|c|c|c|c|c|}
\hline \multirow[b]{2}{*}{ ID } & \multicolumn{2}{|c|}{ Goal Attainment Scaling possible range -2 to +2} & \multicolumn{3}{|c|}{ Moorong Self-efficacy Scale possible range 16-112 } \\
\hline & COPM goal & Score & Baseline & Follow-up & Changed score \\
\hline \multirow[t]{3}{*}{100} & Diet & +1 & 93 & 109 & +16 \\
\hline & Budgeting & +1 & & & \\
\hline & Physical fitness & +2 & & & \\
\hline \multirow[t]{5}{*}{101} & Managing Mitrofanoff & +1 & 91 & 98 & +7 \\
\hline & Asking for less help & 0 & & & \\
\hline & Going out without parents & 0 & & & \\
\hline & Pet care & 0 & & & \\
\hline & Organizing papers & Missing & & & \\
\hline \multirow[t]{3}{*}{102} & Stop procrastinating on schoolwork & +1 & 98 & 109 & +11 \\
\hline & Exercise more & -1 & & & \\
\hline & Nonschool-related hobby & +2 & & & \\
\hline
\end{tabular}

GAS scores were assigned at the completion of Coaching in Context.

ID study identifier, COPM Canadian Occupational Performance Measure.

points and a hobby by three-points, respectively. Participant 101 had three goals that exceeded the two-point improvement in performance, namely, pet care $(+3)$, organizing papers $(+6)$, and emptying her bladder via a catheterizable stoma $(+6)$. Performance in three goals, two identified by participant 100 and one identified by participant 102, was unchanged after coaching, and each participant had one goal that improved by one-point only. In contrast to variation seen in performance improvements, after coaching there was meaningful improvement in satisfaction for every goal, including goals where performance was unchanged or showed small improvement. As examples, despite no meaningful change in performance of budgeting and diet goals, participant 100 reported improved satisfaction with those goals by seven and two points, respectively. Similarly, participant 101 reported a two-point improvement in satisfaction with going out without parents despite little improvement in performance, and participant 102 reported improvement in satisfaction with exercise and procrastination, with negligible change in performance.

One plausible explanation for improved satisfaction is that coaching leads to clearer insights and new understandings about goals, not only about performance, but also about clarity on them, and their importance relative to one's values, deeper desires, and priorities. For example, participant 102 reported an increase in satisfaction with exercise despite no improvement in performance, perhaps due to new insights about his priority for succeeding in pharmacy graduate school (time demands) and a greater appreciation for how few facilities are accessible to wheelchairs. Participant 100 was very satisfied with his performance in budgeting and dieting, despite reporting no improvement in actual performance. In this situation, coaching did not change performance, but did facilitate an awareness about behavior associated with diet and budgeting, and identify actionable behaviors that may support these goals. Further exploration of satisfaction outcomes of Coaching in Context is needed.

The standardized scoring of the COPM was augmented by GAS and is in accordance with the premise of coaching, as it promotes the participant's sense of ownership and responsibility throughout the coaching relationship. Furthermore, through GAS, participants may have obtained additional clarity of what goal achievement would look like since they were active participants in scaling their goals. The GAS also adds precision to assessing goal achievement by tailoring the response categories for each goal. Unlike the COPM scale, GAS provides an explicit description for each of the five response categories and these descriptions are unique for each goal. In this study, one goal was rated as no change in performance on the COPM but was assigned a +1 (a more than expected outcome) (participant 100, dieting) and a -1 (a less than expected outcome) on GAS. Performance of three other goals improved by one COPM point but was assigned a +1 (participant 100, budgeting) and " 0 " (met expected outcome) (participant 101, out with parents) on GAS. Performance in procrastination improved by one COPM point, but on GAS it was assigned a +1 by participant 102. GAS scores may be useful to help interpret COPM satisfaction scores.

MSES showed improvements in self-efficacy related to personal hygiene, sexual relations, social interactions, and perception of the future, which reflect one of the primary outcomes of coaching - that is to generalize problemsolving skills and solution focused thinking to new situations and challenges outside of the coaching relationship. Due to the pilot nature of this study, a direct association between coaching and improved self-efficacy cannot be 
made. However, the study does demonstrate the potential of Coaching in Context's contribution to improved selfefficacy. Further research is warranted.

Although a positive, client-centered framework is common to all coaching approaches, purposes and targeted outcomes are different. Health coaching focuses on behavior change for better self-management of health conditions and reduction of healthcare costs [48, 49]. In health coaching, the relationship between the certified health coach and patient is one of equal partnership, and is formed with the understanding that the responsibility of healthcare costs is shared [50]. Peer health coaching, such as approaches described by Allin et al. [11] and Houlihan et al. [12], focuses on the self-management of SCI-related conditions. As an example, in the SCI \& U peer coaching program [11], participants with SCI select coaching topics from a predefined list of conditions such as pain, skin, bowel, bladder, and sexuality; peers with SCI who are trained as health coaches to talk about the topics and share personal stories and lived experiences.

The results of this study are similar to studies on occupation-based coaching [33] and OPC [30], that showed coaching improves performance in and satisfaction with self-identified goals, as measured by the COPM and GAS. Occupation-based coaching and OPC are occupational therapy interventions used primarily with mothers of young children with ASD. Occupational-based coaching and OPC align well with occupational therapy early intervention that adopts a family-centered and parent-guided approach to practice. While Coaching in Context targets participation outcomes, it is not an occupational therapy intervention, but rather an interprofessional approach that can be offered to persons living with and affected by chronic conditions to optimize everyday living. For some individuals, a goal associated with a medical condition may be highly relevant, as was the case for participant 101 who identified selfcatheterization as a goal for Coaching in Context. The goal of self-catheterization, however, was not selected from a list medical conditions or identified as a goal for Coaching in Context because of high medical costs or poor health, but instead was motivated by the participant's desire to spend time with friends (participation) without a chaperone to assist with emptying her bladder. Likewise, while participant 100 identified "better nutrition" as a goal for Coaching in Context, it was not for weight loss or gain, poor nutrition, or skin problems but rather for general well-being. It is important to distinguish coaching approaches to ensure clients receive the approach that best fits their needs and goals.

Criticisms of coaching in the healthcare literature include the variation and vagueness in coaching methods and protocols, lack of clarity about coach training and competencies, and fidelity to coaching intervention $[9,28,51,52]$. In evaluating Coaching in Context, we were keenly aware of these criticisms and implemented procedures to address them. Coaches were formally trained in coaching techniques and principles by a Certified Positive Psychology Coach, and they demonstrated coaching competencies prior to coaching clients. Coaching frameworks (Fig. 1 and Table 2) were used to structure each coaching session. We audio or video recorded each coaching session, transcribed them verbatim, and used a newly developed fidelity measure for Coaching in Context to assess adherence to core coaching principles. Since there are a limited number of studies that report the direct benefits of interventions on participation in everyday living, and due to the encouraging outcomes of this and other coaching studies, future work should focus on questions about who may benefit from different types of coaching, at what time following SCI different coaching approaches may be most effective, and the optimal dosage for coaching (frequency, duration of each session, and number of sessions).

\section{Limitations}

Several limitations were present in this study. First, developing, scaling, and scoring GAS goals require expertise and objectivity. While recommended methods to develop and scale the GAS were employed, the coaches who assisted with goal writing were the same coaches who implemented Coaching in Context. Additionally, the degree to which coaches adhered to core coaching principles was assessed through the use of a fidelity measure that has recently been developed and that has not been fully validated. It is also plausible that not all coaching sessions were needed or alternatively, more sessions were needed to accomplish goals. Further work is needed to understand optimal dosing of coaching, which we suspect may be less prescriptive and more individualized. Participants who were coached were known to the investigators, and this may have created a bias in favor of Coaching in Context. Finally, while participant 102 completed the study, he had fewer coaching sessions due to the constraints of COVID-19.

\section{Conclusion}

This study illustrates the potential for implementation of Coaching in Context with adults with chronic SCI who seek to enhance their participation in everyday activities.

\section{Data availability}

The data sets generated and/or analyzed during the current study are available from the corresponding author on reasonable request. 
Acknowledgements This research was completed in partial fulfillment of the doctoral degree in occupational therapy at Thomas Jefferson University, Philadelphia, PA by CC, BA, TS, and SB. The study was funded by Thomas Jefferson College of Rehabilitation Sciences, Center for Outcomes and Measurement, Philadelphia, PA. The study was approved by Thomas Jefferson University Institutional Review Board.

\section{Compliance with ethical standards}

Conflict of interest The authors declare no competing interests.

Publisher's note Springer Nature remains neutral with regard to jurisdictional claims in published maps and institutional affiliations.

\section{References}

1. Jonk Y, Lawson K, O'Connor H, Riise KS, Eisenberg D, Dowd $\mathrm{B}$, et al. How effective is health coaching in reducing health services expenditures? Med Care. 2015;53:133-40.

2. Oksman E, Linna M, Hörhammer I, Lammintakanen J, Talja M. Cost-effectiveness analysis for a tele-based health coaching program for chronic disease in primary care. BMC Health Serv Res. 2017;17:138. https://doi.org/10.1186/s12913-017-2088-4.

3. Ditewig J, Blok H, Havers J, van Veenendaal H. Effectiveness of self-management on mortality, hospital readmissions, chronic heart failure hospitalization rate and quality of life in patient with chronic heart failure: A systematic review. Patient Educ Couns. 2010;78:297-315.

4. Patja K, Absetz P, Auvinen A, Tokola K, Kytö J, Oksman E, et al. Health coaching by telephony to support self-care in chronic diseases: clinical outcomes from the TERVA randomized controlled trial. BMC Health Serv Res. 2012;12:147.

5. Benzo R, McEvoy C. Effect of health coaching delivered by a respiratory therapist or nurse on self-management abilities in severe COPD: analysis of a large randomized study. Respir Care. 2019;64:1065-72.

6. Palmer S, Tubbs I, Whybrow A. Health coaching to facilitate the promotion of healthy behaviour and achievement of health-related goals. Int J Health Promot Educ. 2003;41:91-93. https://doi.org/ 10.1080/14635240.2003.10806231.

7. Veen EV, Bovendeert JFM, Backx FJG, Huisstede BMA. Ecoaching: new future for cardiac rehabilitation? A systematic review. Patient Educ Couns. 2017;100:2218-30. https://doi.org/ 10.1016/j.pec.2017.04.017.

8. O'Hara BJ, McGill B, Phongsavan P. Preventive health coaching: is there room to be more prescriptive?. Int J Health Promot Educ. 2016;54:82-94.

9. Dejonghe L, Becker J, Froboese I, Schaller A. Long-term effectiveness of health coaching in rehabilitation and prevention: a systematic review. Patient Educ Couns. 2017;100:1643-53. https://doi.org/10.1016/j.pec.2017.04.012.

10. Nooijen CF, Stam HJ, Sluis T, Valent L, Twisk J, van den BergEmons RJ. A behavioral intervention promoting physical activity in people with subacute spinal cord injury: secondary effects on health, social participation and quality of life. Clin Rehabil. 2017;31:772-80. https://doi.org/10.1177/0269215516657581.

11. Allin S, Shepherd J, Thorson T, Tomasone J, Munce S, Linassi G, et al. Web-based health coaching for spinal cord injury: results from a mixed methods feasibility evaluation. JMIR Rehabil Assist Technol. 2020;7:e16351. https://doi.org/10.2196/16351.

12. Houlihan BV, Everhart-Skeels S, Gutnick D, Pernigotti D, Zazula J, Brody M, et al. Empowering adults with chronic spinal cord injury to prevent secondary conditions. Arch Phys Med Rehabil. 2016;97:1687-95. https://doi.org/10.1016/j.apmr.2016.04.005.

13. Barclay L, Hilton GM. A scoping review of peer-led interventions following spinal cord injury. Spinal Cord. 2019;57:626-35. https://doi.org/10.1038/s41393-019-0297-x.

14. Linden A, Butterworth SW, Prochaska JO. Motivational interviewing-based health coaching as a chronic care intervention. J Eval Clin Pract. 2010;16:166-74. https://doi.org/10.1111/j.13652753.2009.01300.x.

15. Park YH, Moon SH, Ha JY, Lee MH. The long-term effects of the health coaching self-management program for nursing-home residents. Clin Interv Aging. 2017;12:1079-88. https://doi.org/ 10.2147/CIA.S137821.

16. Thom DH, Willard-Grace R, Tsao S, Hessler D, Huang B, DeVore D, et al. Randomized controlled trial of health coaching for vulnerable patients with chronic obstructive pulmonary disease. Ann Am Thorac Soc. 2018;15:1159-68.

17. Tappenden P, Campbell F, Rawdin A, Wong R, Kalita N. The clinical effectiveness and cost-effectiveness of home-based, nurseled health promotion for older people: a systematic review. Health Technol Assess. 2012;16:1-72. https://doi.org/10.3310/hta16200.

18. Magasi S, Heinemann A, Whiteneck G. Participation following traumatic spinal cord injury: an evidence-based review for research. J Spinal Cord Med. 2008;31:145-56. https://doi.org/10. 1097/ADM.0b013e31820c23fa.

19. Schonherr M, Groothoff J, Mulder G, Schoppen T, Eisma W. Vocational reintegration following spinal cord injury: expectations, participation and interventions. Spinal Cord. 2004;42:177-84. https://doi.org/10.1038/sj.sc.3101581.

20. Tomassen PC, Post MW, van Asbeck FW. Return to work after spinal cord injury. Spinal Cord. 2000;38:51-5. https://doi.org/10. 1038/sc.2011.16.

21. Ville I, Winance M. To work or not to work? The occupational trajectories of wheelchair users. Disabil Rehabil. 2006;28:423-36. https://doi.org/10.1080/09638280500192561.

22. Leiulfsrud AS, Ruoranen K, Ostermann A, Reinhardt JD. The meaning of employment from the perspective of persons with spinal cord injuries in six European countries. Work. 2016;55:133-44. https://doi.org/10.3233/WOR-162381.

23. Clifton S. Spinal cord injury and the joy of work. Scand J Disabil Res. 2014;16:377-90. https://doi.org/10.1080/15017419.2013. 813410.

24. Murad SM, Idris SNH, Kannan C, Danis A. Impact of occupationally based intervention program in relation to quality of life of spinal injury people. Procedia Soc Behav Sci. 2016;222:442-9. https://doi.org/10.1016/j.sbspro.2016.05.134.

25. Krause JS, Clark JMR, Saunders LL. SCI longitudinal aging study: 40 years of research. Top Spinal Cord Inj Rehabil. 2015;21:189-200. https://doi.org/10.1310/sci2103-189.

26. Lauren M, Little LM, Pope E, Wallisch A, Dunn W. Occupationbased coaching by means of telehealth for families of young children with autism spectrum disorder. Am J Occup Ther. 2018;72:7202205020. https://doi.org/10.5014/ajot.2018.024786.

27. Little L, Wallisch A, Dunn W, Tomchek T. Telehealth intervention to increase toilet training in Autism. Am J Occup Ther. 2020;74:7411520435. https://doi.org/10.5014/ajot.2020.74S1RP401E.

28. Dunn W, Little LM, Pope E, Wallisch A. Establishing fidelity of occupational performance coaching. OTJR Occup Particip Health. 2018;38:96-104. https://doi.org/10.1177/1539449217724755.

29. Graham F, Rodger S, Ziviani J. Enabling occupational performance of children through coaching parents: three case reports. Phys Occup Ther Pediatr. 2010;30:4-15. https://doi.org/10.3109/ 01942630903337536.

30. Graham F, Rodger S, Ziviani J. Effectiveness of occupational performance coaching in improving children's and mothers' 
performance and mothers' self-competence. Am J Occup Ther. 2013;67:10-8. https://doi.org/10.5014/ajot.2013.004648.

31. Graham F, Rodger S, Ziviani J. Coaching parents to enable children's participation: an approach for working with parents and their children. Aust Occup Ther J. 2009;56:16-23. https://doi.org/ 10.1111/j.1440-1630.2008.00736.x.

32. Kessler D, Egan M, Dubouloz CJ, McEwen S, Graham FP. Occupational performance coaching for stroke survivors: a pilot randomized controlled trial. Am J Occup Ther. 2017;71:7103190020p1-7. https://doi.org/10.5014/ajot.2017.024216.

33. Dunn W, Cox J, Foster L, Mische-Lawson L, Tanquary J. Impact of a contextual intervention on child participation and parent competence among children with autism spectrum disorders: a pretest-posttest repeated-measures design. Am J Occup Ther. 2012;66:520-8. https://doi.org/10.5014/ajot.2012.004119.

34. Potvin M-C, Prelock PA, Savard L. Supporting children with autism and their families: a culturally-responsive family driven interprofessional process. Pediatr Clin North Am. 2018;65:47-57. https://doi.org/10.1016/j.pcl.2017.08.020.

35. Seligman MEP, Csikszentmihalyi M. Positive psychology: an introduction. Am Psychol. 2014;55:5-14. https://doi.org/10.1007/ 978-94-017-9088-8_18.

36. Miller W, Rollnick S. Motivational interviewing: helping people change behavior. 3rd ed. New York: Guilford Press; 2013.

37. Grinnon ST, Miller K, Marler JR, Lu Y, Stout A, Odenkirchen J, et al. National Institute of Neurological Disorders and Stroke Common Data Element project—approach and methods. Clin Trials. 2012;9:322-9. https://doi.org/10.1177/1740774512438980.

38. Law M, Baptiste S, Carswell A, McColl M, Polatajko H, Pollock N. Canadian occupational performance measure. 4th ed. Ottawa: CAOT Publications ACE; 2005. https://doi.org/10.1177/ 000841740507200506.

39. Cup EH, Scholte op Reimer WJ, Thijssen MC, van Kuyk-Minis MA. Reliability and validity of the Canadian Occupational Performance Measure in stroke patients. Clin Rehabil. 2003;17:402-9. https://doi.org/10.1191/0269215503cr635oa.

40. Dedding C, Cardol M, Eyssen IC, Dekker J, Beelen A. Validity of the Canadian Occupational Performance Measure: a client-centred outcome measurement. Clin Rehabil. 2004;18:660-7. https://doi. org/10.1191/0269215504cr746oa.

41. Berardi A, Galeoto G, Guarino D, Marquez MA, De Santis R, Valente D, et al. Construct validity, test-retest reliability, and the ability to detect change of the Canadian Occupational Perfor- mance Measure in a spinal cord injury population. Spinal Cord Ser Cases. 2019;5:52. https://doi.org/10.1038/s41394-019-0196-6.

42. Turner Stokes L. Goal Attainment Scaling (GAS) in rehabilitation: a practical guide. Clin Rehabil. 2009;23:362-70. https://doi.org/ 10.1177/0269215508101742.

43. Kiresuk TJ, Lund SH, Larsen NE. Measurement of goal attainment in clinical and health care programs. Drug Intell Clin Pharm. 1982;16:145-53. https://journals.sagepub.com/doi/abs/10.1177/ 106002808201600201 ? journalCode $=$ aopb.

44. Kiresuk TJ, Sherman R. Goal Attainment Scaling: a general method for evaluating comprehensive community mental health programs. Community Ment Health J. 1968;4:443-53. https://link. springer.com/journal/10597.

45. Miller SM. The measurement of self-efficacy in persons with spinal cord injury: psychometric validation of the Moorong Selfefficacy Scale. Disabil Rehabil. 2009;31:988-93. https://doi.org/ 10.1080/09638280802378025.

46. Middleton JW, Tate RL, Geraghty TJ. Self-efficacy and spinal cord injury: psychometric properties of a new scale. Rehabil Psychol. 2003;48:281-8. https://doi.org/10.1037/0090-5550.48.4.281.

47. Doig E, Fleming J, Kuipers P, Cornwell P. Clinical utility of the combined use of the Canadian Occupational Performance Measure and Goal Attainment Scaling. Am J Occup Ther. 2010;64:904-14. https://doi.org/10.5014/ajot.2010.08156.

48. Olsen JM, Nesbitt BJ. Health coaching to improve healthy lifestyle behaviors: an integrative review. Am J Health Promot. 2010;25. https://doi.org/10.4278/ajhp.090313-lit-101.

49. Palmer S, Tubbs I, Wybrow A. Health coaching to facilitate the promotion of health behavior and achievement of health-related goals. Int J Health Promot Educ. 2003;41:91-93. https://doi.org/ 10.1080/14635240.2003.10806231.

50. Huffman M. Health coaching: a new and exciting technique to enhance client self-management and improve outcomes. Home Healthc Nurse. 2005;25:271-6.

51. Hill B, Richardson H, Skouteris H. Do we know how to design effective health coaching interventions: a systematic review of the state of the literature. Am J Health Promot. 2015;29:158-68. https://doi.org/10.4278/ajhp.130510-LIT-238.

52. Wolever RQ, Simmons LA, Sforzo GA, Dill D, Kaye M, Bechard $\mathrm{EM}$, et al. A systematic review of the literature on health and wellness coaching: defining a key behavioral intervention in healthcare. Glob Adv Health Med. 2013;2:38-57. https://doi.org/ 10.7452/gahmj.2013.042. 